\title{
BMJ Open Seremban Cohort Study (SECOST): a prospective study of determinants and pregnancy outcomes of maternal glycaemia in Malaysia
}

\author{
Heng Yaw Yong, ${ }^{1}$ Zalilah Mohd Shariff, ${ }^{1}$ Zulida Rejali, ${ }^{2}$ \\ Barakatun Nisak Mohd Yusof, ${ }^{1}$ Farah Yasmin, ${ }^{1}$ Lalitha Palaniveloo ${ }^{3}$
}

To cite: Yong HY, Mohd Shariff Z, Rejali Z, et al. Seremban Cohort Study (SECOST): a prospective study of determinants and pregnancy outcomes of maternal glycaemia in Malaysia. BMJ Open 2018;8:e018321. doi:10.1136/ bmjopen-2017-018321

\section{- Prepublication history for} this paper is available online. To view these files, please visit the journal online (http://dx.doi. org/10.1136/bmjopen-2017018321).

Received 23 June 2017 Revised 17 November 2017 Accepted 29 November 2017

\section{Check for updates}

${ }^{1}$ Department of Nutrition and Dietetics, Faculty of Medicine and Health Sciences, Universiti Putra Malaysia, Serdang,

Malaysia

${ }^{2}$ Department of Obstetrics and Gynaecology, Faculty of Medicine and Health Sciences, Universiti Putra Malaysia,

Serdang, Malaysia

${ }^{3}$ Center for Nutrition

Epidemiology Research, Institute for Public Health, Ministry of Health, Kuala Lumpur, Malaysia

Correspondence to

Professor Zalilah Mohd Shariff; zalilahms@upm.edu.my

\section{ABSTRACT}

Introduction Both gestational diabetes mellitus (GDM) and hyperglycaemia less severe than GDM are associated with risk of adverse pregnancy outcomes. We describe the study design of a prospective cohort of pregnant women recruited in early pregnancy with follow-ups of mothers and infants up to 2 years after birth. The primary aim of the study was to identify the determinants and outcomes of maternal glycaemia.

Methods and analysis Seremban Cohort Study

(SECOST) is an ongoing prospective cohort study in which eligible pregnant women in first trimester $(<10$ weeks of gestation) are recruited from Maternal and Child Health clinics in Seremban District, Negeri Sembilan with seven follow-ups during pregnancy through 2 years postnatally. Infants are followed up every 6 months after birth until 2 years old. A standard $75 \mathrm{~g}$ oral glucose tolerance test is performed between 24 and 32 of weeks of gestation and as close to 28 weeks of gestation. Pregnancy and birth information are obtained from medical records.

Sociodemographic, anthropometric, biochemical, dietary, physical activity, smoking, depression, child feeding and other data of mothers and infants are obtained at followups.

Ethics and dissemination This study is approved by the Medical Research Ethics Committee (MREC), Universiti Putra Malaysia (UPM/FPSK/100-9/2-MJKEtika) and MREC, Ministry of Health Malaysia (KKM/NIHSEC/08/0804/P12613). Permission to conduct this study is also obtained from the Head of Seremban District Health Office. All participants are required to provide written informed consent prior to data collection. The research findings will be disseminated at journals and conference presentations.

\section{INTRODUCTION}

During pregnancy, substantial changes occur in glucose, lipid and protein metabolism as to meet the increasing demands of the fetus. In a normal pregnancy, an increase in insulin resistance will reduce glucose uptake into maternal tissues as to make glucose more readily available for fetal growth. This hyperglycaemic state is mainly due to the increased production of placental growth hormones
Strengths and limitations of this study

- SECOST (Sremban Cohort Study) is the first prospective study in Malaysia to provide data on determinants and pregnancy outcomes of maternal glycaemia.

- Information on lifestyle factors and weight gain patterns during pregnancy will provide insight on determinants of maternal glycaemia.

- Data on birth and early child growth patterns will inform on the short-term and long-term outcomes of maternal glycaemia.

- The cohort of pregnant women and their offsprings may not represent the general population of pregnant women and infants in Malaysia due to the location of subject recruitment and study selection criteria.

- High attrition rate of subjects during pregnancy and infancy is expected.

that may interfere with insulin receptor's action and inhibit glucose uptake as pregnancy progresses. ${ }^{1}$ Pregnant women will develop elevated blood glucose level (hyperglycaemia) or gestational diabetes mellitus (GDM) if the mother's beta cells are unable to increase insulin secretion to compensate for the insulin resistance in pregnancy.

The international multicenter Hyperglycemia and Adverse Pregnancy Outcomes study reported that maternal fasting and stimulated glucose levels showed linear associations with risks of increased size at birth, caesarian delivery, neonatal hypoglycaemia and fetal hyperinsulinaemia. ${ }^{2}$ On the basis of this landmark study, the International Association of Diabetes in Pregnancy Study Groups and the American Diabetes Association have recommended new lower diagnostic criteria for GDM. ${ }^{3}$ However, the use of these new criteria has resulted in a dramatic increase in the number of women diagnosed with GDM. ${ }^{4-6}$ Increased healthcare cost and lack 
of improvement in maternal and infant outcomes are other concerns related to the new diagnostic criteria. ${ }^{7}$ Thus, the optimal diagnostic threshold of GDM during pregnancy remains controversial.

Globally, the prevalence of GDM ranging from $1 \%$ to $14 \%$ of all pregnancies, depends on the population and diagnostic criteria of GDM. ${ }^{6}$ In the USA, GDM affected $7 \%$ of all pregnancies annually. ${ }^{8}$ In Europe, a $2 \%-6 \%$ prevalence of GDM was reported with a lower prevalence in the Northern Europe $(<4 \%)$ than in the Southern Europe $(>6 \%) \cdot{ }^{9}$ Similarly, in Asian countries, the prevalence of GDM in China, ${ }^{10}$ Korea $^{11}$ and Thailand ${ }^{12}$ were $6.8 \%, 2 \%-5 \%$ and $5.7 \%$, respectively. GDM rate in Malaysia $(8 \%-11 \%)^{1314}$ is much higher than those reported for most Asian populations $(2 \%-7 \%) \cdot{ }^{10-12}$ As the rate of obesity increases among women, a parallel rise in GDM rate is inevitable. The National Health and Morbidity Survey (NHMS) reported that the prevalence of obesity in Malaysian women aged $\geq 18$ years old increased from $5.7 \%$ in 1996 to $17.6 \%$ in $2011 .{ }^{15} 16$ As more women in reproductive age become overweight or obese prior to pregnancy, they will be at greater risk of maternal hyperglycaemia.

At present, limited data are available on determinants and outcomes of hyperglycaemia during pregnancy in Malaysia. ${ }^{14} 17$ This study will provide important insights on lifestyle factors and weight gain patterns during pregnancy as determinants as well as birth and early child growth data as short-term and long-term outcomes of maternal glycaemia. In light of increasing rates of child and adult obesity, GDM and diabetes mellitus and persistence of child undernutrition in Malaysia, such information on intergenerational transmission of risk of obesity and non-communicable diseases are pertinent for planning effective strategies that best meet the needs and resources to achieve a future healthy generation.

\section{MATERIALS AND METHODS \\ Study design}

SECOST is an ongoing prospective cohort study in which pregnant women and their infants are followed up through 2 years postnatally. Women in the first trimester $(<10$ weeks of gestation) of pregnancy are recruited from three ${ }^{4}$ Maternal and Child Health (MCH) clinics in Seremban District, Negeri Sembilan, Malaysia. There are seven follow-up visits for mothers (three pregnancy and four postnatal visits) and four follow-up visits for infants at an interval of 6 months after birth (table 1).

\section{Participants}

Pregnant women attending MCH clinics for antenatal booking are eligible to participate in the study on screening based on study criteria.

\section{Inclusion criteria}

Malaysian women (age $>18$ years) with singleton pregnancy, body mass index (BMI) $\geq 18.5 \mathrm{~kg} / \mathrm{m}^{2}$ to $<40.0 \mathrm{~kg} /$ $\mathrm{m}^{2}$, normal glycaemia at study enrolment (fasting plasma glucose (FPG) $3.0-6.0 \mathrm{mmol} / \mathrm{L}$ ) and free from any medical illness or obstetrics complications.

\section{Exclusion criteria}

Women with multiple pregnancies, became pregnant with assistance of advanced reproductive technology, unable to complete oral glucose tolerance test (OGTT) within 24-32 weeks of gestation, pre-existing diabetes mellitus (FPG $>7.0 \mathrm{mmol} / \mathrm{L}$ ), diagnosis of diabetes during this pregnancy, abnormal glycaemia (FPG $<3.0 \mathrm{mmol} / \mathrm{L}$ or FPG $>6.0 \mathrm{mmol} / \mathrm{L}$ ) at study enrolment, previous diagnosis of diabetes requiring treatment with medication outside of pregnancy, BMI $>40.0 \mathrm{~kg} / \mathrm{m}^{2}$, other medical problems (eg, HIV positive, hepatitis B or hepatitis C, hypertension, renal disease, anaemia, thalassaemia) at study enrolment.

\section{Recruitment}

Study information leaflet is given to all pregnant women attending the three $\mathrm{MCH}$ clinics for antenatal booking by nurses. Pregnant women who meet the selection criteria are invited to participate in the study. Study participation is on a voluntary basis and participants can withdraw from the study at any time during the study period. A study manual that outlines the details of study visits and measurements are given to participants. The period of recruitment is from 2013 to 2016.

\section{Sample size}

Sample size is estimated using a statistical formula for a proportion by Scheaffer et al. ${ }^{18}$ Based on $18.3 \%$ of pregnant women in Malaysia had abnormal OGTT, ${ }^{19} 95 \%$ confidence level and 5\% probability of missing a true difference, a minimum of 230 pregnant women are required as study participants. To account for an attrition rate of $50 \%$, the sample is increased to a minimum of 345 pregnant women.

\section{Measurements}

The schedule of measurements for mothers and infants at study enrolment and follow-up visits are summarised in table 1.

\section{Mothers}

\section{Sociodemographics}

The sociodemographic information obtained include current age, years of education, ethnicity, marital status, occupation, income, spouse's years of education, spouse's occupation, spouse's income and household income.

\section{Dietary intake}

Dietary intake is assessed using 24-hour dietary call for 1 day and Food Frequency Questionnaire (FFQ).

\section{Energy and nutrient intakes}

A 24-hour diet recall is used to obtain dietary information. Standard household measuring cups, glasses, bowls and spoons are used to assist respondents to estimate food portion size. Dietary data are analysed using Nutritionist 

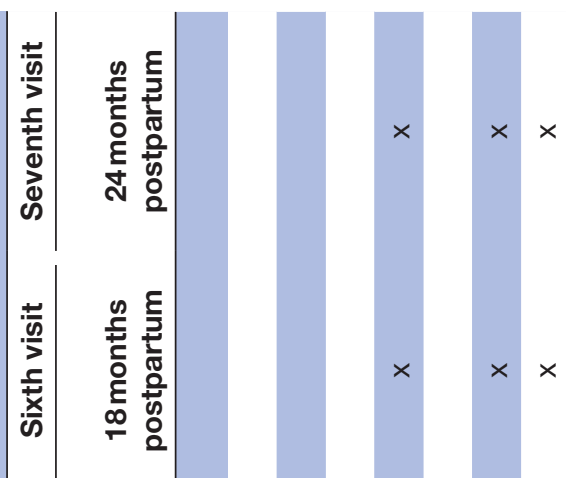

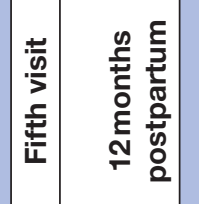

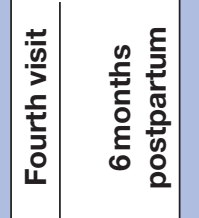

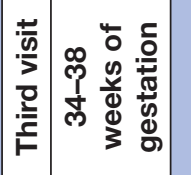

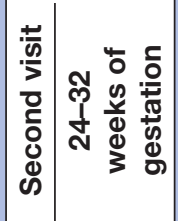

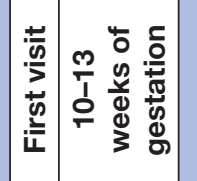

$\times \times$

$\times \times \times \times$

$\times \times \times \times$

$\times \times \times \times$

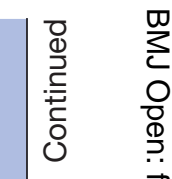

$\stackrel{\vec{F}}{\stackrel{2}{9}}$

$\frac{\bar{c}}{\frac{\bar{c}}{\overline{5}}}$

$\frac{8}{\infty}$

$\overrightarrow{\vec{\partial}}$

ळ.

$\frac{0}{3}$

กิ

ํ.

$\stackrel{\mathscr{N}}{\underline{O}}$

옥

N

峁

$\stackrel{N}{\circ}$

일

$\sum_{0}$

$\stackrel{\circ}{\circ}$

$\overrightarrow{\overrightarrow{0}}$

吾

흥.

$\stackrel{\frac{10}{9}}{\frac{1}{9}}$

훙.

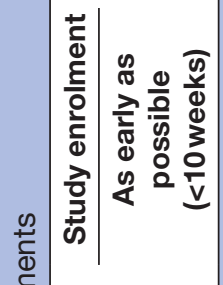

$x \times \quad \times \quad \times \quad \times \quad \times \quad \times \quad \times \quad \times$

일

을.

N

N

远

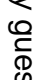

들

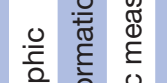

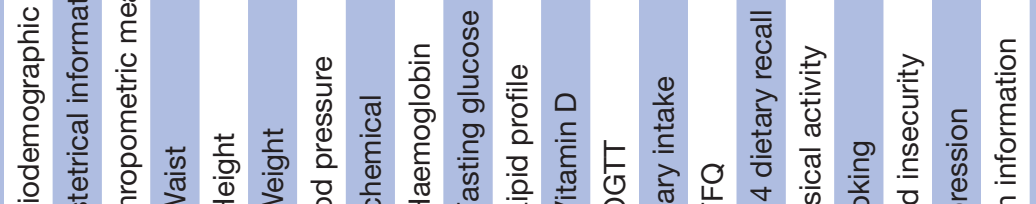

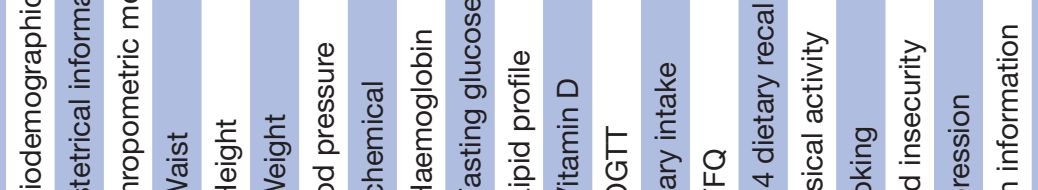

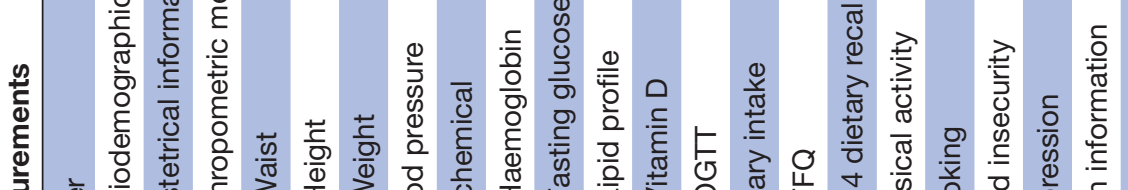

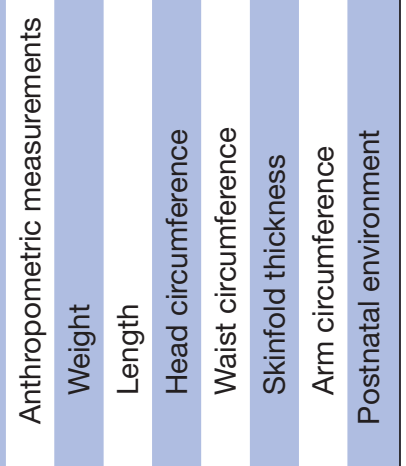

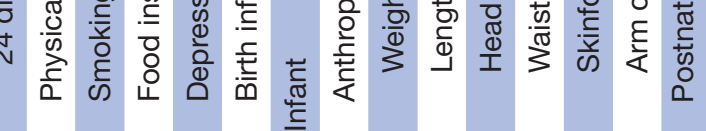




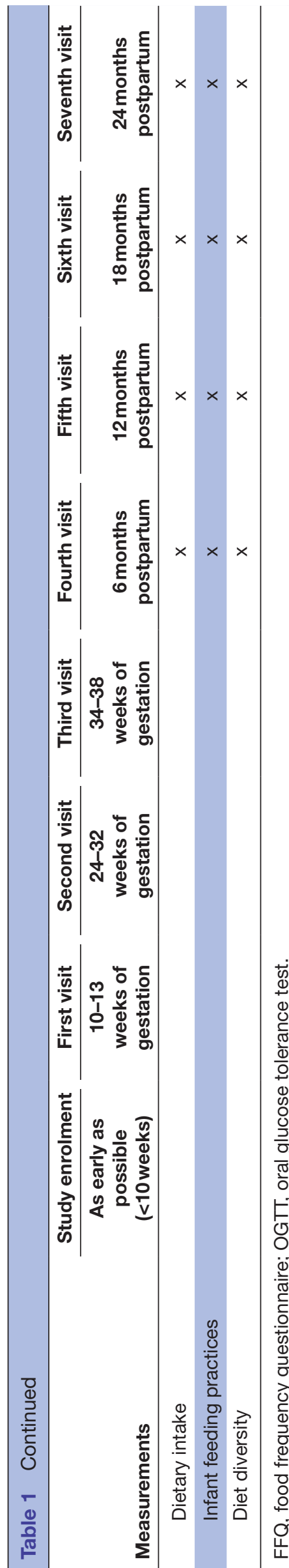

Pro Diet Analysis software,${ }^{20}$ and comparison of energy and nutrient intakes is made to the Malaysian Recommended Nutrient Intake ${ }^{21}$ to determine intake adequacy. Intakes of grains, meat, fish, legumes, fruits, vegetables and dairy product $(\mathrm{g} /$ day) are calculated as number of servings and compared with the Malaysian Dietary Guidelines. $^{22}$

\section{Alcohol use}

The frequency of drinking alcohol and amount of alcohol (glass) are obtained.

\section{Energy density}

Energy density is calculated by dividing each subject's daily energy intakes (in kilocalories) by the reported weight of all foods consumed (in grams). ${ }^{23}$

\section{Dietary pattern}

FFQ is used to assess food consumption patterns. There are 12 main food groups with 50 subfood groups which include cereals, meat and meat products, fish and seafood, eggs, fruits, vegetables, legumes and nuts, milk and dairy products, fat and oil, sugar and sugary food and flavouring and beverages. ${ }^{24}$ Dietary patterns are determined based on standard procedures. ${ }^{25} 26$

\section{Dietary glycaemic index and glycaemic load}

Dietary glycaemic index (GI) and glycaemic load (GL) are calculated from FFQ and 24-hour dietary recall. The GI values will be categorised into low GI: $\leq 55$, medium GI: 56-70 and high GI: $>70$. The formulae to calculate dietary GI and GL as used are: ${ }^{27-29}$

Dietary GI $=($ GI value of the food $\times$ frequency of servings of the food per day $(\mathrm{g}) \times$ carbohydrate content of the food $(\%)$ )/total daily carbohydrate $(\mathrm{g})$.

Dietary GL $=($ GI value of the food $\times$ frequency of servings of the food per day $(\mathrm{g}) \times$ carbohydrate content of the food $(\%)$ ).

\section{Physical activity}

Pregnancy Physical Activity Questionnaire (PPAQ) is used to determine physical activity of pregnant women. ${ }^{30}$ The PPAQ is a semiquantitative questionnaire that requires participants to report the time spent participating in 32 activities including household/care giving (13 activities), occupational (5 activities), sports/exercise (8 activities), transportation (3 activities) and inactivity (3 activities).

\section{Anthropometry}

Weight, height and waist circumference are measured at study enrolment (antenatal booking) using standard instrument (SECA digital weighing scale, SECA body metre and SECA measuring tape). Prepregnancy body weight (current pregnancy) and weight at the beginning of first pregnancy are obtained from medical record. Prepregnancy BMI is calculated as prepregnancy weight (kilogram) divided by recommendation of WHO. ${ }^{31}$ Interpregnancy weight change is defined as the difference between weight at the beginning of the first and current 
pregnancies. Postpartum weight retention is calculated as the absolute difference between weight measured at each of fourth and fifth visit and prepregnancy weight. Total gestational weight gain is defined as the difference between measured weight at last prenatal visit and prepregnancy weight. Rate of weight gain in first, second or third trimester is defined as the average weekly weight gain in that trimester.

\section{Biochemical}

A standard $75 \mathrm{~g}$ OGTT is performed at two time points. The first OGTT is performed for all participants at 10-13 weeks of gestation. The second OGTT is performed between 24 and 32 weeks of gestation (second visit) and as close to 28 weeks of gestation as possible. A $2 \mathrm{~mL}$ fasting venous blood is drawn prior to ingestion of a standard glucose solution. Another $2 \mathrm{~mL}$ of venous blood is drawn at 2 hours after ingestion of standard glucose solution. All blood samples are sent for analysis on the same day to determine fasting glucose, 2-hour plasma glucose concentration. Additional blood $(3 \mathrm{~mL})$ is obtained for analysis of total cholesterol, HDL-cholesterol, triglycerides and vitamin D. Normal FPG for pregnant women is defined according to the Ministry of Health $(\mathrm{MOH})(3.0 \mathrm{mmol} / \mathrm{L}$ to $<6.0 \mathrm{mmol} / \mathrm{L}$ ). The cut-off values for serum lipid is according to the National Cholesterol Education Program Adult Treatment Panel III $^{32}$ guidelines. Vitamin D cut-offs for severe deficiency, mild deficiency, insufficiency and sufficiency are $<25 \mathrm{nmol} / \mathrm{L}, 25$ to $<50 \mathrm{nmol} / \mathrm{L}$, 50 to $<75 \mathrm{nmol} / \mathrm{L}$ and $\geq 75 \mathrm{nmol} / \mathrm{L}$, respectively. ${ }^{33}$

\section{Blood pressure}

Right arm systolic blood pressure and diastolic blood pressure is measured using OMRON SEM-1 Automatic Blood Pressure Monitor by trained nurses.

\section{Smoking habit}

The status of smoking, frequency of smoking and number of cigarettes smoked are obtained.

\section{Food insecurity}

A 10 items questionnaire is use to assess women food insecurity. All items are rated on a three response point ranging from always, sometimes or never. ${ }^{34}$

\section{Depression}

Depression during pregnancy and postpartum depression is assessed using a self-administered 10 question Edinburg Postnatal Depression Scale. ${ }^{35}$

\section{Maternal birth information}

\section{Delivery}

Mode of birth (normal vaginal birth, assisted breech delivery, instrumental delivery or caesarean section) and gestational age at birth are obtained from medical record. Premature birth is defined as childbirth occurring at less than 37 completed weeks of gestation or 259 days of gestation. ${ }^{36}$

\section{Birth information of infants}

Birth data are obtained from medical record. Birth weight is categorised according to the recommendation of Unicef and WHO. ${ }^{37}$ SGA is defined as an infant weighing less than 10th percentile of birth weight. An infant with $>90$ th percentile of birth weight was classified as large-for-gestational age (LGA), while an infant with the 10th-90th percentile of birth weight as appropriate-for-gestational age. ${ }^{38}$

\section{Infants}

\section{Anthropometry}

All infants are measured for weight (to the nearest $0.1 \mathrm{~kg}$ ), length (to the nearest $0.1 \mathrm{~cm}$ ), head circumference and mid arm circumference (to the nearest $0.1 \mathrm{~cm}$ ) using TANITA digital baby weighing scale with recumbent length metre and SECA fibreglass measuring tape, respectively. Infants are measured using standard procedures as described by Gibson. ${ }^{39}$ Growth data are analysed using Anthro Plus software that uses WHO growth standard. ${ }^{40}$ Five growth indicators (weight-for-age, weight-for-height, height-for-age, head circumference-for-age and BMI-age) will be determined. In order to assess subcutaneous fat, triceps and subscapular are measured using Harpenden Skinfold Caliper and recorded to the nearest $0.1 \mathrm{~mm} .{ }^{41}$

\section{Dietary intake}

A 24-hour diet recall is used to obtain dietary information of infants from parents / guardians with the aid of standard household measurements. Dietary data are then analysed for adequacy of energy and nutrients ${ }^{20}$ as well as dietary diversity. ${ }^{42}$ Parents are also interviewed on infant feeding practices (eg, milk feeding and complementary feeding).

\section{Data collection}

All enumerators are given an intensive briefing and field training before data collection. Study visits are scheduled on the same day of appointments at $\mathrm{MCH}$ clinics. A day before each visit, enumerators are required to remind participants of their clinic appointments through telephone calls. During the visits, participants are interviewed or measured for relevant data. For participants who are not able to be interviewed at the clinics, home visits or telephone interviews are carried out by enumerators.

\section{Data analysis}

Data will be analysed using IBM SPSS Statistic V.22. Descriptive statistics (mean, SD, median and frequency) will be used to describe the data. Multiple logistic regression will be used to determine the relationship between predictors and maternal glycaemia, as well as the relationship between maternal glycaemia with pregnancy outcomes controlling for confounding variables. Significant level for all statistical analysis will be set at $\mathrm{P}<0.05$.

\section{DISCUSSION}

Globally, the prevalence of overweight and obesity is increasing among women, particularly during 
reproductive years. A study on trends of obesity in the USA showed that the prevalence of obesity (BMI $\geq 30 \mathrm{~kg} / \mathrm{m}^{2}$ ) in US women aged 20-39 years increased from $28.4 \%$ in 1999 to $34.0 \%$ in $2007 .{ }^{43}$ In the Malaysian National Health and Morbidity Survey ${ }^{15}$ (NHMS II), women showed a significantly higher prevalence of obesity (BMI $\geq 30 \mathrm{~kg}$ / $\left.\mathrm{m}^{2}\right)(17.5 \%)$ than man $(10.2 \%)$. In the period between the NHMS II (1996) and the NHMS (2011), there was an $11.9 \%$ increase in the prevalence of obesity (BMI $\geq 30 \mathrm{~kg}$ / $\mathrm{m}^{2}$ ) among females aged $\geq 18$ years old. With increasing prevalence of obesity among women of childbearing age, the risk of having higher prepregnancy BMI and excessive gestational weight gain are inevitable. ${ }^{44} 45$ These conditions could further increase the risk of pregnant women to have higher blood glucose level and subsequently poor pregnancy outcomes.

Studies have shown that women with hyperglycaemia during pregnancy are at higher risk for poor pregnancy outcomes, such as caesarean delivery, pregnancy induced hypertension and pre-eclampsia. ${ }^{19} 4647$ Apart from that, mothers with hyperglycaemia during pregnancy tend to have LGA infants and infants with asphyxia and hypoglycaemia. ${ }^{47-49}$ These conditions can lead to other long-term child health problems such as obesity, type 2 diabetes, cancer and cardiovascular disease in later life. For the mothers with hyperglycaemia, they are at higher risk of developing cardiovascular disease and overt diabetes, mainly type 2 diabetes in later life. ${ }^{50-52}$ However, there is no clear threshold above which women are at high risk and below which they are at low risk. Moreover, the impact of maternal hyperglycaemia, which is characterised by value of glucose tolerance intermediate between normal and gestational diabetes on outcomes of pregnancy remains unclear.

Dietary intake and physical activity are important modifiable risk factors for the development of type 2 diabetes, as well as gestational hyperglycaemia. While higher total fat and lower carbohydrate intakes during second trimester of pregnancy were associated with maternal hyperglycaemia, ${ }^{53}$ pregnant women in the high quartile of moderate intensity activity and occupational activity during early pregnancy had about $50 \%$ decreased risk of abnormal glucose tolerance. ${ }^{54} \mathrm{~A}$ lower energy intake and higher physical activity are known to improve insulin sensitivity and reduce glucose levels, however, there is less information on dietary nutrients intakes, particularly fat types, vitamin $\mathrm{D}$ and iron related to maternal hyperglycaemia, as well as the optimal distribution of macronutrient intakes during pregnancy to prevent maternal hyperglycaemia. Therefore, there is a need for a better understanding of the role of lifestyle factors, especially energy and nutrient intakes, physical activity and sedentary behaviour in the development of maternal hyperglycaemia.

SECOST is the first prospective study in Malaysia to provide a better understanding of weight gain and lifestyle patterns from early pregnancy until 1-year postpartum and to quantitate the relationship between maternal glucose levels and pregnancy outcomes. As GDM impacts maternal and fetal health, detailed information on lifestyle factors, biochemical parameters and weight gain patterns during pregnancy can provide insight on determinants of maternal glycaemia. Data on early child growth and development obtained periodically will provide information on short-term and long-term outcomes of maternal glycaemia and indicate the role of environment (eg, infant feeding, diet, parent-infant interaction and home environment) that could potentially impact child growth and development. Despite the modest sample size, this pregnancy cohort study provides an opportunity for many hypotheses related to maternal and infant health and nutrition to be tested or confirmed. SECOST is expected to provide valuable data that can be used for strengthening existing strategies and formulating new strategies that are in accordance with promoting MCH.

Acknowledgements The authors would like to thank all women and infants who took part in this study and all nurses, and staff in $\mathrm{MCH}$ clinics of Seremban district, Negeri Sembilan for their assistance during data collection.

Contributors ZMS conceptualised and designed the study; contributed to the development of study protocol; supervise data collection; read, revised and approved the final draft of manuscript. YHY conceptualised and designed the study, contributed to the development of study protocol, involved in data collection, drafted the manuscript, read and approved the manuscript. ZR and BNMY contributed to the development of study protocol, read and approved the manuscript. FY and LP involved in data collection, read and approved the manuscript.

Funding Funding is provided by Danone Dumex (Malaysia) Shd. Bhd.

Competing interests None declared.

Patient consent Obtained.

Ethics approval This study is approved by the Medical Research Ethics Committee (MREC), Universiti Putra Malaysia (UPM/FPSK/100-9/2-MJKEtika) and the Medical Research Ethics Committee (MREC), Ministry of Health Malaysia (KKM/ NIHSEC/08/0804/P12-613). Permission to conduct this study is also obtained from the Head of Seremban District Health Office.

Provenance and peer review Not commissioned; externally peer reviewed.

Author note As the nature of this study is more of exploratory and does not involve any testing of company product, the researchers are free to report any findings of this study in future publications.

Open Access This is an Open Access article distributed in accordance with the Creative Commons Attribution Non Commercial (CC BY-NC 4.0) license, which permits others to distribute, remix, adapt, build upon this work non-commercially, and license their derivative works on different terms, provided the original work is properly cited and the use is non-commercial. See: http://creativecommons.org/ licenses/by-nc/4.0/

(c) Article author(s) (or their employer(s) unless otherwise stated in the text of the article) 2018. All rights reserved. No commercial use is permitted unless otherwise expressly granted.

\section{REFERENCES}

1. Perkins JM, Dunn JP, Jagasia SM. Perspectives in gestational diabetes mellitus: a review of screening, diagnosis, and treatment. Clinical Diabetes 2007;25:57-62.

2. Metzger BE, Lowe LP, Dyer AR, et al. HAPO Study Cooperative Research Group. Hyperglycemia and adverse pregnancy outcomes. N Engl J Med 2008;358:1991-2002.

3. Panel IA of D and PSGC. International Association of Diabetes and Pregnancy StudyGroups Recommendations on the Diagnosis and Classification of Hyperglycemia in Pregnancy. Diabetes Care [Internet] 2010;33:676-82. Available from: http://care. diabetesjournals.org/content/33/3/676.short. 
4. Cundy T, Ackermann E, Ryan EA. Gestational diabetes: new criteria may triple the prevalence but effect on outcomes is unclear. $B M J$ 2014;348:g1567.

5. Blackwell SC. Counterpoint: enough evidence to treat? The American college of obstetricians and gynecologists guidelines. Clin Chem 2012;58:1098-100.

6. Coustan DR. Medical management of pregnancy complicated by diabetes. 5th edn. Virginia: American Diabetes Association, 2013.

7. Langer O, Umans JG, Miodovnik M. Perspectives on the proposed gestational diabetes mellitus diagnostic criteria. Obstet Gynecol 2013;121:177-82.

8. Hillier TA, Vesco KK, Pedula KL, et al. Screening for gestational diabetes mellitus: a systematic review for the U.S. preventive services task force. Ann Intern Med 2008;148:766-75.

9. Buckley BS, Harreiter J, Damm P, et al. Gestational diabetes mellitus in Europe: prevalence, current screening practice and barriers to screening. A review. Diabet Med 2012;29:844-54.

10. Zhang $Y$, Peck K, Spalding M, et al. A study to examine the attitudes, knowledge, and utilization of CAM by primary care professional in West Texas. Complement Ther Med 2010;18:227-32

11. Jang HC. Gestational diabetes in Korea: incidence and risk factors of diabetes in women with previous gestational diabetes. Diabetes Metab J 2011;35:1-7.

12. Sumeksri P, Wongyai $S$, Aimpun P. Prevalence of gestational diabetes mellitus (GDM) in pregnant women aged 30 to 34 years old at Phramongkutklao Hospital. J Med Assoc Thai 2006;89 (Suppl 4):S94-9.

13. Kwapisz J, Bodaghi M. In: Jeganathan R, Karalasingam SD, eds. Preliminary report of national obstetrics registry, Jan--December 2010. Kuala Lumpur, Malaysia: National Obstetrics Registry and the Clinical Research Centre (CRC), Ministry of Health Malaysia, 2013:1-24.

14. Tan PC, Ling LP, Omar SZ. Screening for gestational diabetes at antenatal booking in a Malaysian university hospital: the role of risk factors and threshold value for the 50--g glucose challenge test. Aust N Z J Obstet Gynaecol 2007:47:191-7.

15. Institute for Public Health, Ministry of Health. NationAl Health and Morbidity Survey 2011 (NHMS 2011). Kuala Lumpur, Malaysia: Institute for Public Health, Ministry of Health, 2011:258.

16. Institute for Public Health, Ministry of Health. The second National Health and Morbidity Study (NHMS 2). Kuala Lumpur, Malaysia: Institute for Public Health, Ministry of Health, 1996.

17. Kampan N, Azman H, Hafiz I, et al. Outcome of pregnancy among Malaysian women with diabetes mellitus -- a single centre experience. Malaysian J Public Heal Med 2013;13.

18. Scheaffer R, Mendenhall W, Ott R, et al. Elementary survey sampling. 7th edn. Massachusetts, United States: Cengage Learning, 2011:480 pages.

19. Nordin NM, Wei JW, Naing NN, et al. Comparison of maternal-fetal outcomes in gestational diabetes and lesser degrees of glucose intolerance. J Obstet Gynaecol Res 2006;32:107-14.

20. Axxya Systems LLC. Nutritionist pro diet analysis. 2011. http://www. axxya.com/products.html

21. National Coordinating Committee on Food and Nutrition. Recommended Nutrient Intakes for Malaysia. A report of the technical working group on nutritional guidelines. Putrajaya: Ministry of Health Malaysia, 2005.

22. National Coordinating Committee on Food and Nutrition. Malaysian Dietary Guidelines 2010. A report of the technical working group on nutritional guidelines. Putrajaya: Ministry of Health Malaysia, 2010.

23. Ledikwe JH, Blanck HM, Kettel Khan L, et al. Dietary energy density is associated with energy intake and weight status in US adults. Am $J$ Clin Nutr 2006;83:1362-8.

24. Ministry of Health Malaysia. The Malaysian Adults Nutrition Survey (MANS)--findings report 2003. Putrajaya, Malaysia: Nutrition Section Family Health Development Division, Ministry of Health Malaysia, 2007.

25. Randall E, Marshall JR, Graham S, et al. Patterns in food use and their associations with nutrient intakes. Am J Clin Nutr 1990;52:739-45.

26. Nicklas TA, Webber LS, Thompson B, et al. A multivariate model for assessing eating patterns and their relationship to cardiovascular risk factors: the Bogalusa Heart Study. Am J Clin Nutr 1989;49:1320-7.

27. Sieri S, Krogh V, Berrino F, et al. Dietary glycemic load and index and risk of coronary heart disease in a large italian cohort: the EPICOR study. Arch Intern Med 2010;170:640-7.
28. Villegas R, Liu S, Gao YT, et al. Prospective study of dietary carbohydrates, glycemic index, glycemic load, and incidence of type 2 diabetes mellitus in middle-aged Chinese women. Arch Intern Med 2007;167:2310-6.

29. Liu S, Willett WC. Dietary glycemic load and atherothrombotic risk. Curr Atheroscler Rep 2002;4:454-61.

30. Chasan-Taber L, Schmidt MD, Roberts DE, et al. Development and validation of a pregnancy physical activity questionnaire. Med Sci Sports Exerc 2004;36:1750-60.

31. World Health Organization. Physical status: the use and interpretation of anthropometry. Geneva: World Health Organization. 1995. WHO Technical Report Series No. 854

32. National Cholesterol Education Program (NCEP) Expert Panel on Detection, Evaluation, and Treatment of High Blood Cholesterol in Adults (Adult Treatment Panel III). Third report of the national cholesterol education program (NCEP) expert panel on detection, evaluation, and treatment of high blood cholesterol in adults (Adult Treatment Panel III) final report. Circulation 2002;106:3143-421.

33. Jan Mohamed HJ, Rowan A, Fong B, et al. Maternal serum and breast milk vitamin D levels: findings from the Universiti Sains Malaysia pregnancy cohort study. PLoS One 2014;9:e100705.

34. Radimer KL, Olson CM, Campbell CC. Development of indicators to assess hunger. J Nutr 1990;120(Suppl):1544-8.

35. Cox JL, Holden JM, Sagovsky R. Detection of postnatal depression. Development of the 10-item Edinburgh postnatal depression scale. Br J Psychiatry 1987;150:782-6.

36. World Health Organization. International classification of diseases and related health problems. 10th edn. Geneva: World Health Organization, 1992

37. United Nations Children's Fund and World Health Organization. Low birthweight: country, regional and global estimates. New York: United Nations Children's Fund and World Health Organization, 2004.

38. Bukowski R, Hansen NI, Willinger M, et al. Fetal growth and risk of stillbirth: a population-based case-control study. PLoS Med 2014;11:e1001633.

39. Gibson RS. Principles of nutritional assessment. Oxford, United Kingdom: Oxford University Press, 2005:908.

40. World Health Organization. Training course on child growth assessment. Geneva: World Health Organization, 2008.

41. Dauncey MJ, Gandy G, Gairdner D. Assessment of total body fat in infancy from skinfold thickness measurements. Arch Dis Child 1977;52:223-7.

42. Food and Agriculture Organization and Food and Nutrition Technical Assistance Project. Guidelines for measuring household and individual dietary diversity. Rome, Italy: FAO, 2013.

43. Flegal KM, Carroll MD, Ogden CL, et al. Prevalence and trends in obesity among US adults, 1999-2008. JAMA 2010;303:235-41.

44. Gunderson EP. Childbearing and obesity in women: weight before, during, and after pregnancy. Obstet Gynecol Clin North Am 2009:36:317-32

45. Li N, Liu E, Guo J, et al. Maternal prepregnancy body mass index and gestational weight gain on pregnancy outcomes. PLoS One 2013;8:e82310.

46. Catalano PM, Tyzbir ED, Wolfe RR, et al. Carbohydrate metabolism during pregnancy in control subjects and women with gestational diabetes. Am J Physiol 1993;264(Pt 1):E60-7.

47. Lowe LP, Metzger BE, Dyer AR, et al. Hyperglycemia and Adverse Pregnancy Outcome (HAPO) study: associations of maternal $\mathrm{A} 1 \mathrm{C}$ and glucose with pregnancy outcomes. Diabetes Care 2012;35:574-80.

48. Leary J, Pettitt DJ, Jovanovic L. Gestational diabetes guidelines in a HAPO world. Best Pract Res Clin Endocrinol Metab 2010;24:673-85.

49. Polin RA, Fox WW, Abman SH. Fetal and neonatal physiology. Philadephia, PA: Elsevier Health Sciences, 2011.

50. Gilmartin AB, Ural SH, Repke JT. Gestational diabetes mellitus. Rev Obstet Gynecol 2008;1:129-34.

51. Negrato CA, Gomes MB. Historical facts of screening and diagnosing diabetes in pregnancy. Diabetol Metab Syndr 2013;5:22.

52. Carr DB, Utzschneider KM, Hull RL, et al. Gestational diabetes mellitus increases the risk of cardiovascular disease in women with a family history of type 2 diabetes. Diabetes Care 2006;29:2078-83.

53. Ley SH, Hanley AJ, Retnakaran R, et al. Effect of macronutrient intake during the second trimester on glucose metabolism later in pregnancy. Am J Clin Nutr 2011;94:1232-40.

54. Chasan-Taber L, Silveira M, Lynch KE, et al. Physical activity before and during pregnancy and risk of abnormal glucose tolerance among hispanic women. Diabetes Metab 2014;40:67-75. 